\title{
"Concerto», ein Beitrag zur Auflösung von Dissonanzen in Tariffragen
}

\author{
Jürg Schlup \\ Dr. med., Präsident der FMH
}

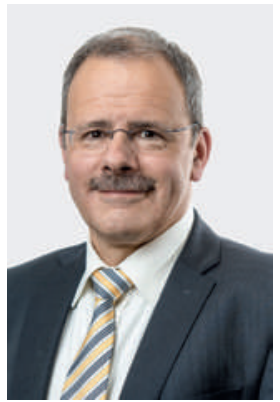

Gerade im Gesundheitswesen, das alljährlich nach Bekanntgabe der Prämien schweizweit ein vertrautes Klagelied erklingen lässt, bergen alle Fragen rund um das Thema Tarife - und erst recht Tarifanpassungen Konfliktpotential. Einigkeit besteht lediglich darüber, dass die Tarifstruktur TARMED nach über zehn Jahren nicht mehr sachgerecht sein kann - und somit Revisionsbedarf besteht. Nur: Welchen inhaltlichen Ansprüchen muss eine revidierte Struktur gerecht werden? Und vor allem: Welche gesetzlichen Vorgaben muss sie erfüllen?

\section{Welche gesetzlichen Vorgaben muss eine revidierte Tarifstruktur tatsächlich erfüllen?}

Über Fragen wie diese gehen die Meinungen auseinander. Je nach Perspektive betrachten die Akteure vor allem die Sachgerechtigkeit und die Gewährleistung einer qualitativ hochstehenden medizinischen Versorgung als prioritär - oder stellen mit Verweis auf Wirtschaftlichkeit und Billigkeit Forderungen nach Kostenneutralität in den Vordergrund. Die divergierenden Positionen machten es erforderlich, auf Basis wissenschaftlicher Expertise Klarheit zu schaffen. Damit unser Mammutprojekt zur Tarifanpassung ein Erfolg wird, benötigen wir fundierte Analysen und Interpretationen des gesetzlichen Rahmens, an denen sich die Revision ausrichten und messen lassen kann.

Das Projekt "Concerto" bezog darum verschiedene Wissenschaftsdisziplinen ein, die mit Hilfe ihrer spezifischen Instrumente die Begriffe und Vorgaben vor allem des Krankenversicherungsgesetzes ergründeten und erläuterten. Wir sind sehr froh, dass wir für dieses anspruchsvolle Projekt namhafte Experten mit ganz verschiedenen Blickwinkeln gewinnen konnten. Deren Einschätzungen können nun im Buch Tarif und Tarifanpassung in der Krankenversicherung nachgelesen werden. So erläutert Prof. Dr. iur. U. Kieser von der Warte des Juristen aus, was gesetzlich festgelegt ist und was nicht -, Dr. oec. HSG W. Oggier geht auf gesundheitsökonomische Aspekte ein und Dr. sc. nat. et med. A. Bührer wirft in seinem Beitrag einen metho- dischen Blick auf Tarifmodell, -struktur und -pflege im ambulanten Bereich.

Ebenso erfreulich ist auch, dass trotz der widerstreitenden Interessen in diesem Feld und trotz der unterschiedlichen Herangehensweisen die Autoren eine für sie selber «teilweise höchst überraschende grosse Einheitlichkeit in der Interpretation der entsprechenden Bestimmungen" feststellen konnten. Die Übereinstimmungen der Experten zeigen auf, dass Tarife, Tarifstrukturen und Tarifanpassungen eben nicht beliebig in Abhängigkeit von Gutdünken, politischer Couleur und Kassenstand gehandhabt werden können. Es gibt einige gut begründbare Grundsätze und Leitlinien, die weitgehend unbestritten sein sollten.

Dies betrifft nicht nur das Grundziel einer qualitativ hochstehenden Versorgung $\mathrm{zu}$ möglichst geringen Kosten, wobei - glücklicherweise - die Versorgung als primäres Ziel gilt. Die Lektüre nährt auch den Zweifel an der Statthaftigkeit des gegenüber der Ärzteschaft geforderten doppelten Kostenneutralitätsgebots, das sowohl statische als auch dynamische Kostenneutra-

Auf Ebene des Tarifs werden sich die Probleme des Gesundheitswesens nicht lösen lassen und so sieht es das KVG auch nicht vor.

lität verlangt. Die berechtigte Forderung der Prämienzahler, dass die Tarifrevision keinen Kostenschub verursachen soll, darf nicht dazu führen, dass der TARMED zum Ausgleich steigender Kosten herhalten muss. So würden die ambulant tätigen Ärzte für Demographie, medizinischen Fortschritt und Inanspruchnahmeverhalten in Haftung genommen. Auf Ebene des Tarifs werden sich die Probleme des Gesundheitswesens nicht lösen lassen - und so sieht es das KVG auch nicht vor.

Dank des beeindruckenden Engagements des Departements Ambulante Tarife und der Ärztekasse liegt nun eine wissenschaftliche Grundlage für einen fairen Ausgleich der Interessen vor. Zu hoffen bleibt, dass dieses Concerto einige Dissonanzen auflösen kann und uns einem möglichst harmonischen tarifarischen Schlussakkord näher bringt. 